\title{
Analysis of Relating the Use of a Learning Management System to Teacher Epistemology and Course Characteristics in Higher Education
}

\author{
Chiaki Iwasaki* \\ Division of Teaching and Learning \\ Kansai University \\ 3-3-35, Yamate-cho Suita city Osaka, Japan \\ E-mail: ciwasaki@kansai-u.ac.jp
}

\section{Toshiya Tanaka}

Faculty of Letters

Kansai University

3-3-35, Yamate-cho Suita city Osaka, Japan

E-mail: ttank@kansai-u.ac.jp

\section{Kenichi Kubota}

Faculty of Informatics

Kansai University

2-1-1 Reizenji-cho Takatsuki city Osaka, Japan

E-mail:kubota@res.kutc.kansai-u.ac.jp

*Corresponding author

\begin{abstract}
This study proposes appropriate methods for supporting instructors in the development of course plans by explaining how the use of a learning management system (LMS) relates to teachers' epistemology and course characteristics. By analyzing the data, the authors identified three categories of courses taught at undergraduate levels: (1) knowledge construction, (2) knowledge transmission, and (3) mixed. In knowledge construction courses, instructors need to transform students' conceptions of learning and the LMS must support, among other things, students' cognition and interaction. Teaching assistants, typically graduate students who work directly with the instructor, are also needed for enhancing instruction of these courses. In knowledge transmission courses, instructors need to relate the knowledge learned in the course with the competencies required by society, and the LMS should include functions for evaluating students' learning progress. Teaching assistants for these courses should support student learning, especially for those with poor comprehension of the content. In mixed courses, instructors need to make communication with individual students visible to the whole class and the LMS should include functions for promoting student interaction. Finally, the authors propose that an organization for supporting improved instruction should implement development learning models based on instructor's epistemology and course characteristics in order to facilitate LMS utilization based on lesson strategies. Also they should conduct case studies with teachers who have problems fostering collaborative learning and disseminate the lessons from
\end{abstract}


these case studies to other instructors.

Keywords: Learning Management System; Epistemology; Teacher's Support; Active Learning; Higher Education

Biographical notes: Chiaki Iwasaki is an assistant professor of Educational Technology at Kansai University, Japan. She received Ph.D. degree in Informatics from Kansai University. Her research includes: The Design of Learning Environment in Higher Education, Active Learning utilizing Learning Management System, and Teacher's and Learner's Support for Active Learning.

Toshiya Tanaka is a professor of Psychology at Kansai University, Japan. He received Ph.D. degree in Psychology from Nagoya University. His research includes: Psychology of Thinking, Problem Solving, and Cognitive Psychology. Specific interests in the field of education are the relationships between teacher's philosophy on teaching-learning processes and utilization of ICT.

Kenichi Kubota is a professor of Educational Technology at Kansai University, Japan. He received Ph.D. degree in Educational Technology from Indiana University. His research includes: The Design of Learning Environment using Web.2.0, Participatory International Development, and Communication in Development.

\section{Introduction}

The Ministry of Education, Culture, Sports, Science and Technology in Japan has identified the need to improve the quality of teaching in higher education (MEXT, 2008). This assessment reflects the fact that university education has become increasingly "universal" in Japan (Trow, 1976), which has presented educators with problems such as decreased motivation and declining academic ability. Increasingly, for help in solving these problems educators have looked to learning methodologies or university assistance (Tanaka, 2003), including remedial courses, small group instruction, or utilization of Teaching Assistants. Another solution is Learning Management Systems (LMS), which have been adopted by Japanese universities since the 1990s. In 2007, 52 percent of all Japanese universities were employing LMS (NIME, 2008). Harashima (2009) identified the merits of LMS as promoting "active learning not limited to a specific time or classroom," "communication between instructor and students," and "collaborative learning among students.". For example, Yamamoto (2009) used an LMS to conduct quizzes and allow students to review lessons, so that they could learn at their own pace. Okano and Kubota (2006) employed Bulletin Board Systems (BBS) in large-sized classes to promote discussion among students. As a result, the students asked questions to other students and exhibited a high degree of understanding of learning tasks. Despite such identified benefits, however, LMS has not been disseminated widely in Japan. One reason is that Japanese universities do not provide comprehensive support for instruction (Yoshida \& Taguchi, 2005; Yien, 1999). If universities fail to provide adequate support for implementation, it will be difficult to disseminate LMS use. 


\section{Research Objectives}

The purpose of this research is to analyze how the use of a learning management system relates to teachers' epistemology and course characteristics, and propose appropriate methods for supporting instructors in the development of course plans. In this research, we will assess LMS as a support tool for classroom-based courses, not for on-line elearning courses; because on-line courses are not yet popular in Japan, most universities use LMS in their regular courses (NIME, 2008).

\section{Status of LMS Use in Japan}

Although, as noted above, the benefits of utilizing LMS in the classroom have been widely noted, instruction using LMS remains uncommon in Japan (Yoshida \& Taguchi, 2005). One reason is the lack of instructor training. Japanese faculties have few opportunities to participate in training on utilizing LMS in classroom instruction and there are few mechanisms for sharing instructional know-how among instructors (Taguchi, 2007). Those instructors who want to learn how to use LMS effectively in classroom instruction typically cannot get the assistance they need (Nakai \& Saito, 2007). Thus, although universities are increasingly called on to meet the needs of instructors and support instruction, support systems and practice-based information remain inadequate in Japan (Matsuda, 2004). Many universities try to implement LMS through a trial and error process, so it is necessary to create strong support systems (Yoshida \& Taguchi, 2005).

\section{Support System Based on Teachers' Epistemology and Course Characteristics}

The university body responsible for strengthening teaching effectiveness should propose appropriate methods for utilizing LMS depending on instructors' needs. However, university courses come in many forms, and each instructor has his or her individual teaching methods. If the teaching support group offers the same kind of assistance to all instructors, it will be difficult to meet their needs. Effective implementation requires development of support models for LMS utilization. We selected teaching epistemology and course characteristics as distinguishing factors when constructing such a model. Ishida, Itoh, and Kajita (1986) describes instructors' beliefs concerning solving problems in classroom instruction. However, because instructor's beliefs include their ideas about students, classroom instruction, and the university, this category is too broad to be appropriate as the basis for creating a model. For this reason we decided upon teachers' epistemology. Ideas about students and classroom instruction are predicated on the process of constructing knowledge. For example, an instructor's concepts of classroom design relate to their ideals of student behavior, and their concepts about ideal students are based on student knowledge, so knowledge construction is based on epistemology. Therefore, epistemology refers to concepts based on instructors' beliefs (Matsuo, 2006). Kajita (1986) and Tanaka (1999), who researched the relationship between utilizing computers and an instructor's epistemology, concluded that instructors' epistemology is related to their computer utilization. It can thus be said that we should understand the epistemology of the instructor in order to be able to take an indicator of analysis. The other component, course characteristics, is said to be related to teaching methods (Silber, 2007). One of the course characteristics that are relevant to this study is "diverse responses to questions" (Silber, 2007). For example, pedagogy and literature typically 
encourage diverse responses, while physics and mathematics, which allow only one correct answer, do not. Silber (2007) writes that if a learning task is determined clearly, the learning method will be clear too. Accordingly, if a learning task is not determined clearly, the learning method will not be clear. Therefore, it is said that learning methods are related to course characteristics (Tanaka, 1999; Tanaka, Iwasaki, \& Saio, 2008). We also asked whether or not the course emphasizes sequential lessons. However, since some degree of sequencing is common to all courses it might be difficult to use this characteristic to distinguish types of courses. Because courses can be clearly divided into those that promote diverse responses to questions and those that do not, we adopted diverse responses as a distinguishing course characteristic. For the reasons noted above, we selected the course characteristic of diverse responses and instructors' epistemology to help us select appropriate support methods. However, very little research has been conducted in this area in Japan.

\section{Subject of Research}

\subsection{About Kansai University and Learning Management System CEAS}

We chose Kansai University as the subject of this research. Kansai University is a very large private university with thirteen departments, 27,914 students and 679 full-time faculty members in May 2010. Kansai University has adopted an LMS called CEAS, which is designed to support course-related activities for both instructors and students. Functions available to an instructor are those related to dissemination of readings and assignments, materials for use in the class, and review assignments and so on (Okamoto et al., 2007). The functions also include support for classroom tests and questionnaires and student evaluations at the end of the semester. About three hundred faculty members used CEAS during 2008.

\subsection{The Methods for Supporting LMS}

The university provides system management services for the LMS, such as instruction on registering for a university course and manuals how to use LMS provided through the Internet. They also offer the "CEAS Community Page," a BBS that provides consultation for system-related problems, and responds to requests about adding and improving functions of CEAS. In addition, the Web site introduces case studies using LMS, showing classroom instruction in a few courses as instructional services.

\section{Research Methodology}

The authors selected for study twenty instructors who utilized LMS in their regular classes. They were chosen from among fifty instructors who had been identified as heavy users of LMS for effective instruction. The criteria used for selection, aiming to select motivated teachers, included type of course, class size and sponsoring faculty. The chosen instructors teach courses that include "Research on American literature," "Practicum for sociology," "Western philosophy," "Market management," "Accounting Institutions," "Urban planning" and "Programming.". The instructors belong to many different faculties, including letters, sociology, engineering, commerce, and economics. The objective was to collect instructors' opinions in order to clarify the relationship of LMS use to instructor epistemology and course characteristics. 
The authors developed a questionnaire based on previous studies concerning instructors' epistemology and course characteristics (Tanaka, 1999; Silber, 2007) using a five-point scale. About epistemology, we asked instructors to evaluate if their course was student-centered, and if it emphasized exchanges of opinion among students. To understand instructor epistemology, we asked how the instructor incorporates students' actions. That is because, most instructors who believe that knowledge results from transferring information effectively instruct in a didactic manner, while most instructors who believe that knowledge can be constructed via interaction among students are willing to apply an active learning style in classroom instruction. The research of Silber (2007) and Tanaka (1999) also focuses on these aspects in a questionnaire. Having selected diverse responses as the targeted course characteristic, we also asked instructors about such criteria as "the learning tasks in this course are well-structured," "The learning tasks in this course are poorly structured," and "This course emphasizes fostering original opinions." Interviews were held individually, with each requiring 1-1.5 hours. We asked the subjects how and why they utilize LMS, their objectives, the functions of LMS, its effectiveness and problems they have identified in using LMS in teaching according to their current teaching methods. In addition, the subjects were asked to provide more complete explanations for their responses on the questionnaire and about their previously written reports on LMS use in classroom instruction. The interview responses were transcribed after the interview, with about 10-15 pages of data (A-4 size) recorded for each instructor.

The analysis was carried out by first plotting the results of the questionnaire, and classifying them provisionally as indicators of instructors' epistemology and course characteristics. As an indicator of teacher's epistemology, we looked at emphasis on students' activities. As an indicator of course characteristics, we used diverse responses. Secondly we reconfirmed the results of classification by analyzing interview data. Third we analyzed the interview data according to grounded theories. On the basis of this analysis, we introduced categories and labels for each type of course, and then identified appropriate methods for supporting instructors in creating course plans by explaining how the use of a LMS relates to the teachers' epistemology and course characteristics.

\section{Results and Interpretation}

By analyzing the data, the authors identified three categories: (1) knowledge construction courses, (2) knowledge transmission courses, and (3) mixed courses. As a result of coding, we constructed fifteen categories, 35 sub-categories and 180 labels. Then we identified common categories, sub-categories and labels. A breakdown of common categories can be seen in Table 1 .

Table1. Data for common categories, sub-categories and labels based on course types

\begin{tabular}{|c|c|c|c|}
\hline & Categories & Sub-categories & Labels \\
\hline Knowledge construction courses & 5 & 6 & 12 \\
\hline Knowledge transmission courses & 5 & 5 & 13 \\
\hline Mixed courses & 5 & 7 & 14 \\
\hline
\end{tabular}




\subsection{Analysis of Knowledge Construction Courses}

Instructors of knowledge construction courses want to foster ways of thinking in order to nurture ideal students, so they promoted creating opportunities for students to think by themselves, rather than only transmitting knowledge to students. One of these methods is utilizing BBS and promoting exchanges of opinions among students. BBS is utilized as a support tool for group work (Instructor A, B, C and G), and as a tool to promote communication between the instructor and students, and among students themselves (Instructor D, E and $\mathrm{H}$ ) for classes of over three hundred students. In classes that implement group work, students post comments on group work activity on the BBS, so they can share their results and information with other groups. Instructor B, who teaches an English class, has students post their comments on group work and classroom instruction. He said that he wanted students to improve their vocabulary use in English by sharing information about their groups. Previously it was difficult to know what other groups were doing. However by utilizing LMS, students could learn about other groups' activities and share opinions and practice English expressions. By reading other students' posts, student could review their own knowledge of English usage, and they learned new English expressions. Among instructors who utilize BBS in large classes, many post discussion themes on the BBS after the class, then student post their opinions. Instructors can ask students to read other students' opinions. Instructor D said one of the purposes of this course was to encourage students to think about their ideas and cultivate a broader point of view. In ordinary classes, instructors do not allow students to share their opinions with other students. By using BBS, however, instructors give students the opportunity to know about other students' ideas, which encourages them to develop broader perspectives and thus improves the quality of classroom instruction.

Therefore, instructors who use BBS treat it as tool to promote review of material presented in class. In knowledge construction courses, knowledge is gained by critical thinking and by students' comparing their ideas to those of others (Kubota, 2000), so instructors can promote student thinking through the application of BBS functions. Instructors can also assess the level of participation and understanding of each student by reading the BBS record. Characteristic of this type of course is an emphasis on diverse responses, so instructors need to review and foster knowledge by having students exchange opinions and by introducing new perspectives. Courses with open-ended tasks are better suited than highly structured tasks to this course style, and BBS is a good tool for promoting these activities. It should be noted that most instructors of this type of course are in liberal arts disciplines and many of the courses included here are liberal arts courses. Instructors identified some problems with BBS use, such as students copying their posts from other Websites and posting as many comments as possible in order to achieve a greater number of posts. Some students do not think deeply or adopt a positive attitude to collaborative learning among students, and such behavior can reduce the motivation of other students in the class. These problems need to be addressed in the future.

\subsection{Appropriate Methods for Supporting Instructors of Knowledge Construction Courses}

The instructors of knowledge construction courses utilize BBS functions on LMS, and they typically emphasize students' diverse responses. To implement these classes, we will suggest some appropriate methods below. 


\section{Necessity to transform students' ideas about learning}

Instructors noted that students' cooperation is needed in participatory learning, yet many students adopt a passive attitude, and they prefer to passively learn and remember the information presented in class. Many students lack experience in exchanging opinions with other students or making comments. If the instructor thinks it is important for students to share their opinions and for students to review each other's comments, the instructor will promote greater student thought. However it is clear that students tend to perceive that knowledge is something that is transmitted directly from instructor to student. There is a need to transform students' conceptions of learning by promoting opportunities for student discussions and allowing students to share their opinions.

\section{Developing new functions that support student reflection and interaction among students}

CEAS are developed as support tools for classroom instruction, so they include functions that allow instructors to check whether students have gained knowledge using quizzes and reports. However instructors in knowledge construction courses place greater value on exchanges of ideas among students and group work, and CEAS does not offer full support in these areas. For these instructors, CEAS should offer new functions such as the ability to develop a number of BBS, a function that allows instructors to check the number of posts and on-line visits by each student, and a function that allows students to read each other's comments and append their opinions. There is a need for expanded functions and interface to support student learning, including a list of each student's posts and related comments from other students. These types of functions will promote more student reflection and improved organization of student exchanges.

\section{Introducing teaching assistants - graduate students who work directly with the teacher}

Teaching assistants can play an important role as agents to promote interaction among students in this type of course. Kansai University is currently implementing a trial teaching assistant system, but instructors must now find teaching assistants by themselves. In the future, a teaching assistant system should be put in full operation with support provided to instructors who are not supervising graduate school students and thus find it difficult to identify proper candidates. A continuing program for hiring teaching assistants can be a motivating force for graduate students.

\subsection{Analysis of Knowledge Transmission Courses}

The common features of knowledge transmission courses include the transmission of basic knowledge, competencies required by society, and applied skills utilizing basic knowledge as ways of nurturing ideal students. Courses that fall in this category are typically science and technology courses. In these courses, instructor can clearly identify the learning content and prepare sequential lessons, so it is easy to identify competencies required by society. Instructors think students need to learn basic knowledge and applied skills utilizing basic knowledge to nurture competencies required by society, and that knowledge transmission is the important way to nurture this literacy. Also it is easy to gauge whether students have acquired skills and knowledge with quizzes and assignments, because correct responses can be identified. In addition, instructors recognize the importance of the problem of a wide disparity in students' academic ability and motivation. To solve these problems, Instructors $\mathrm{N}, \mathrm{O}$ and $\mathrm{P}$ prepared quizzes using LMS, and they encouraged students to prepare and review for the class in order to 
decrease the wide disparity in the academic ability of students. Instructor P said that since students often lack basic knowledge, he needs to offer additional educational support, including promotion of greater preparation and review, so he posts handouts on the LMS before the class. Students read these handouts and then check their understanding of important words by taking a preparatory quiz before the class. After receiving classroom instruction they take another quiz as a follow-up review. As a result of these activities, average scores on the final examination, which were typically in the range of forty to fifty points, increased to eighty to ninety points, the instructor said. Instructor O implemented similar techniques; this instructor noted that "students recorded improved scores" and that this effort promoted student "autonomous learning." Science and technology courses are sequential courses with clearly structured problem-based learning tasks, so instructors can utilize quiz functions to test basic knowledge easily. However, another problem has arisen an increasingly wide disparity in the academic ability of students, making it difficult to foster applied skills utilizing basic knowledge. Instructor $\mathrm{P}$ said that students find it burdensome to take quizzes after every class, and some students stop taking the tests. As a result, there is a rising disparity in the academic ability of students between those who practice preparation and review and those who do not before doing it.

\subsection{Appropriate Methods for Supporting Instructors in Knowledge Transmission Courses}

In knowledge transmission courses, instructors utilize the quiz function to nurture basic knowledge and to decrease the disparity in the academic ability of students. However if a gap increases in students' motivation, then academic ability will exhibit growing disparity. In view of these facts, the authors suggest the following support be provided.

\section{Relating the knowledge learned in the course to competencies required by society}

One of the reasons that the gap in academic ability tends to increase is that students are unable to appreciate the importance of basic knowledge. Instructor L said that students want to design architectural works, but often they do not understand the connection of design and basic knowledge in fields like mathematics. He said that he wants students to gain architectural skills but they do not understand the importance of basic knowledge. Instructors identify competencies required by society as qualities to be found in ideal students, so they want students to learn basic knowledge of the course and applied skills utilizing basic knowledge. However students tend to focus on completed products, and do not appreciate the importance of basic knowledge, such as building design calculations and specifications. Therefore, instructors need to demonstrate how basic knowledge relates to architecture in real life. This may include giving quizzes to improve basic knowledge related to society and offering comments to students related to their interests, encouraging them to complete tasks, and fostering a sense of confidence and accomplishment (Suzuki, Nojima, \& Yoshida, 2006). There are other methods that can be useful in courses like computer programming, for example, having students form project teams to develop software systems for virtual clients. In this way, coursework approximates real-world processes in developing computer software. By participating in project teams, student will nurture basic knowledge and acquire applied skills utilizing basic knowledge. This example underscores the importance of including real-world methods in classroom instruction. 


\section{LMS should be equipped with functions to assess student learning}

Instructors wanted to try motivating students by showing the distribution of test scores. Instructors usually place more importance on student participation in class and on assessing understanding than on scores generated by utilizing the quiz function. To promote learner autonomy, we need to encourage students to gain confidence while they try to solve individual questions (Suzuki, Nojima, \& Yoshida, 2006). It is necessary for students to understand their academic strengths and weaknesses after reflecting on their study progress, so the LMS should provide new functions that assess students' academic progress and clarify students' class standing to make the learning process more transparent and to enhance student motivation.

\section{Teaching assistants should support student learning, especially for those with poor understanding of the content}

Even if instructors relate the knowledge learned in the course to the competencies required by society, students who lack basic knowledge will not be able to complete the learning tasks. In addition, it is difficult to offer individual support to students in a large classroom. Given these difficulties, there should be greater promotion of a teaching assistant system to support student learning, especially for students with a poor grasp of the material. Teaching assistants should possess adequate instructional skills, including the ability to identify reasons for poor performance on tests and to offer appropriate support.

\subsection{Analysis of Mixed Courses}

Teachers in mixed courses generally value the importance of autonomous learning, promoting opportunities for independent thinking, and having opinions as part of their educational philosophy, and they promote active learning. However, this kind of course does not emphasize diverse responses, so instructors tend to assume that they need teach basic knowledge first, even if they want to implement active learning. If the students have not mastered basic knowledge, it would be difficult for instructors to promote "active learning" methods such as discussion and opinion exchanges among students. Instructor $\mathrm{Q}$, a teacher of urban planning, pointed out that it is necessary for students to first possess specialized knowledge before exchanging their opinions. Instructor $Q$ explained that because the class aims to disseminate basic knowledge he emphasizes traditional passive learning, noting that without a good grasp of basic knowledge it would be difficult for students to exchange their opinions. Thus, in mixed courses understanding of basic knowledge takes precedence. If the students fail to master these basic principles it's likely that problems such as inadequate comprehension or misunderstandings may arise. Due to the characteristics of mixed courses, therefore, instructors of these courses implement "passive learning" to transfer knowledge. However instructors also contrive means to implement active learning. For example, they may include blanks in their handouts for students to fill in by themselves, in order to promote a more active learning approach. Instructor R provides handouts before class and promotes students' autonomous learning. Then after class he quizzes students to assess their understanding and sometimes posts comments about the quiz on LMS. Instead of a final test, instructor R assesses performance with a quiz after every class and three reports. Since instituting these new methods students' class attendance has greatly increased. In addition, the average student assessment when asked on class surveys if instruction is easy to understand increased from 3.9 to 4.7 on a five-point scale. Many instructors emphasize "feedback to students," so they often comment individually to students. Instructors think it is difficult for students 
to discuss among themselves but they can communicate and engage in interactions with students individually. Instructor R said, "I hope students will understand basic knowledge in the course. I want to teach and support students who can learn more and study independently. Instructor $\mathrm{R}$ answered questions from highly motivated students using LMS and promoted "active learning" as an ideal instruction mode by promoting interaction between instructor and students. Therefore, instructors of mixed courses utilize the quiz function of LMS, and they nurture basic knowledge. However, they also emphasize interaction between instructor and student and take advantage of the opportunity to receive written questions and feedback on LMS. They support motivated students by offering students more opportunities to think, and they contrive means of promoting autonomous learning.

\subsection{Appropriate Methods for Supporting Instructors in Mixed Courses \\ Making communication with individual students visible to the whole class}

Instructors communicate with individual students when they answer their questions or address their comments, increasing the opportunities for autonomous learning. In the future, it would be beneficial to make these individual exchanges visible to the entire class so that other students can view these interactions by introducing students' comments in class or by posting them to the LMS. Displaying communication with students is a good way to motivate other students and introduce new ideas and perspectives.

\section{The LMS should be equipped with the functions that promote interaction among students}

Mixed courses include fundamental concepts and content, so instructors may think it is difficult for students to exchange ideas before they have mastered the material. However some teachers try to initiate student discussions. Instructor $\mathrm{E}$ tried to promote student discussions on a BBS on a trial basis; he commented that he was surprised at the degree of active discussion and posited that students hold opinions to a greater degree than they are assumed to by most instructors. In mixed courses, instructors often communicated with individual students, although they want to implement active learning. In these situations, there is a need to provide greater opportunities for promoting communication with students and among students, such as displaying comments by students on other students' reports on a trial basis. By sharing their comments with other students, students will compare their writing with that of others, promoting greater reflection and motivation.

\section{Discussion}

Based on the results explained here, the authors propose appropriate methods for supporting instructors in the development of course plans. The optimal way to utilize LMS is different for each type of course, but instructors can devise means of fostering a learning environment that will promote active learning. Knowledge construction courses need to change students' perspectives on learning to promote active learning. Knowledge transmission courses need to implement methods to improve students' motivation for active learning. Mixed courses need means to change from fostering individual communication between teacher and student to fostering student communication with each other. 
All instructors are eager to support students' autonomous learning, although the method of utilizing LMS is different for each type of course. To that end, there should be more efforts made to develop appropriate new LMS functions and a Teaching Assistant system. CEAS functions support the transmission of knowledge from instructor to student, however this is not enough to promote active learning and autonomous learning. It will be desirable to develop functions that vary according to the type of course, such as functions that classify comments on a BBS and allow students and instructors to comment on each other's reports and exchange views, and others that allow instructors to access archival records for quizzes or to access the student's overall scholastic standing to assist in student course evaluations.

In addition, we identified the importance of TAs for promoting learning utilizing LMS, while recognizing that the roles of TAs vary depending on the type of course. In knowledge construction courses, instructors should rely on TAs' skills in facilitating communication by asking students' opinions and summarizing discussions, rather than expecting specialized experience or instruction skills. On the other hand, in knowledge transmission courses, instructors want TAs with specialized experience and knowledge, which can transmit basic knowledge of the subject in a way that's easily understood. In the future, instructors should have opportunities for collaboration for nurturing TAs and sharing effective methods for utilizing TAs in course instruction.

Finally, we identified the need to support instructional design to promote active learning, new functions to satisfy instructors' needs and an active TA system. The existing organization for supporting instructors specializes in system support and methods of LMS operation. In the future, it should provide instructional support to promote active learning in classroom instruction. We also realized that some common problems in classroom instruction are difficult for the teacher to solve independently, so a support organization needs to implement a collaborative approach with these teachers. The existing approach is categorized by waiting for inquiries from instructors via email or website forms, and then responding to specific requests. However, the organization should take a more proactive approach to solicit instructors' opinions about utilizing LMS and to identify possible problems and solutions to improve the effectiveness of LMS utilization.

\section{Conclusion and Future Directions}

This study proposed appropriate methods for supporting instructors in the development of course plans by explaining how the use of a learning management system (LMS) relates to the teachers' epistemology and the course's characteristics. By analyzing the data, the authors identified three categories of courses taught at undergraduate levels: (1) knowledge construction, (2) knowledge transmission, and (3) mixed. In the future, the university's LMS support system should identify factors that affect instructors' utilization of LMS, such as the instructors' epistemology and course characteristics. To promote that objective, we intend to collect more data on classroom practice, and implement supportive measures more widely among the faculty. 


\section{References}

1. Harashima, H. (2009). e-learning kara Blended learning he. [From e-learning to Blended learning]. Tokyo: Editted by Miyaji, K. , Kyoritushuppan

2. Ishida, S., Itoh, A., \& Kajita, M. (1986). Shou Chugakkou Kyoshi no Sidou Koudou no Bunseki: Sansuu/ Suugaku niokeru Kyouin no Kojin reberu no shidouan. [Personal teaching theory of elementary and junior high school teacher on mathematics]. Journal of Educational sociology. 34(3), 230-238

3. Kubota, K. (2000). Kouseishugi Paradaimu to Gakushu Kankyo Dezain. "The paradigm of Constructivism and Learning Environment”. Osaka: Kansai University Press

4. Matsuda, T. (2004). Project base no e-learning Dounyu - Senmonteki Jinzai no Ikusei he Mukete-. [Project-based e-Learning - Human Resources Development of 'e-Learning Professionals' ]. Journal of multimedia aided education research, $l 1,73-84$.

5. Matsuo, R. (2006). Keiken kara no Gakushu. [Learning based on experience]. Tokyo: Doubunkan shuppan

6. Ministry of Education, Culture, Sports, Science and Technology (MEXT). (2008). 2008 nendo Gakko Kihonchosa Sokuhou [News of school information research on 2008]. Tokyo: Ministry of Education, Culture, Sports, Science and Technology.mnhj

7. Nakai, T., \& Saito, Y. (2007). Daigaku Kyoiku no Shitsu wo Sougouteki ni Koujyou saseru Kenshu Kyozai. [Learning materials for collaborative enhancement of undergraduate education]. Journal of multimedia aided education research, 4, 31-40.

8. National Institute of Media Education (NIME). (2008). e-learning tou no ICT wo Katsuyoshita Kyoiku nikansuru Cyosa Houkokusho. [Research on e-learning utilization]. Tokyo: National Institute of Media Education.

9. Okamoto, K., Dan, H., Yamamoto, E., \& Fuyuki, M. (2007). Consolidative ESP. Proceeding of the 2007 IEEE International Professional Communication Conference (IPCC 2007).

10. Okano, T., \& Kubota, K. (2006). Densikeijibann ni Miru Daigakusei no Media ni taisuru Ishiki Henyo no Katei to Sonoyoin no Bunseki. [Analysis of the transformation of students' ideas about the media through BBS]. Research of Educational Media, 12(2), 1-16.

11. Silber, H.K. (2007). A Principle-Based Model of Instructional Design: A new way of thinking about and teaching ID. Educational Technology, 47(5), 5-19.

12. Suzuki, K., Nojima, E., \& Yoshida, A. (2006). Ningen Kagaku to e-learning. "Human information science and e-learing". Tokyo: Zaidan hojin Housou Daigaku Kyouiku Sinkokai.

13. Taguchi, M. (2007). FD Suishinkikan niokeru Futatsu no Kinou. [Two functions of FD center or committee for faculty development]. Journal of multimedia aided education research, 4 (1), 53-63.

14. Tanaka, T. (1999). Tishiki Kakutoku/Unyo nikansuru Kyoshi no Tetsugaku to Kyoshitu niokeru Computer riyouno Kanren (1). [The relationship between teachers' philosophy of knowledge acquisition: Utilization and classroom behavior 
around computers]. Annual report of Kansai University research center for teacher training course, 13, 37-92.

15. Tanaka, T. (2003). Daigaku Kyoiku Gaku. [Pedagogy in Higher Education]. Tokyo:Baifukan.

16. Tanaka, T., Iwasaki, C., \& Saio K. (2008). Kyoin no Motsu Kyokaninshiki, Oshie, Manabi no Tetsugaku to ICT Katsuyo Keitai no Kankei. [Relation of teachers' epistemology and course characteristics]. Heisei 20 nendo Japan Universities Association for Computer Education Kyoiku Kaikaku IT Senryaku Taikai, 70-71.

17. Trow, M. (1976). Kougakureki Shakai no Daigaku [Universities in a higher education society]. Tokyo: Tokyo Daigaku Shuppankai.

18. Yamamoto, H. (2009). e-learning kara Blended learning he. [From e-learning to blended learning]. Tokyo: Editted by Miyaji, K. ' Kyoritushuppan.

19. Yien, F. (1999). Daigaku niokeru Media Riyo Sisutemu -Sanso Model wo Motiita Jirei Bunseki- [Multimedia Application System in Higher Education: A ThreeLayer Model and Its Application]. Journal of multimedia aided education research, l2, 1-14.

20. Yoshida, A., \& Taguchi, M. (2005). Mosaku Sareru e-learning. [e-learning Groping]. Tokyo: Toshindo. 